\title{
Measurement of Individual Differences in Intake of Green and Yellow Vegetables and Carotenoids in Young Unmarried Subjects
}

\author{
Keisuke Hosotani and Masahiro KitagawA ${ }^{1}$ \\ Faculty of Education, Wakayama University, Wakayama 640-8510, Japan \\ ${ }^{1}$ Otemae College of Nutrition, Osaka 540-0021, Japan
}

(Received April 15, 2005)

\begin{abstract}
Summary In this study, a dietary survey for 3 weekdays of young unmarried subjects [workers and students, 159 males and 160 females, ages 18-19y (17.2\%), 20-24 y (56.2\%), 25-29 y (18.6\%), 30-34 y (6.7\%) and $35 \mathrm{y}-(1.3 \%)]$ was performed. We evaluated the intake of green and yellow vegetables in this survey and determined the carotenoids ( $\beta$-carotene, $\alpha$-carotene, lycopene, $\beta$-cryptoxanthin, and lutein + zeaxanthin) in 15 kinds of green and yellow vegetables frequently consumed. The carotenoid intake of each subject was calculated from the intake of these vegetables and the amount of carotenoid. Moreover, we studied the intake of protein, fat, and dietary fiber, and investigated its relationship to the intake of vegetables. The mean green and yellow vegetable intake/d in all subjects was $60.5 \pm 58.7 \mathrm{~g}$, much lower than the recommended level [120 g/d, (Health Japan 21 by Japanese Ministry of Health, Labour and Welfare)]. The intake of green and yellow vegetables was greater in females than males, and in workers than students. In all subjects, the mean total carotenoid intake/d was 2,852.8 $\pm 2,354.3 \mu \mathrm{g}$. In the total intake of carotenoids, there was no difference between males and females; however, the intake was greater in workers than in students. The intake of $\beta$-carotene and $\alpha$-carotene was greater in males than females. However, the intake of $\beta$-cryptoxanthin, lycopene, and lutein+zeaxanthin was greater in females than males. The group with the low green and yellow vegetable intake had not only a low carotenoid intake, but also a low intake of protein, fat, and dietary fiber. Therefore, it was suggested that carotenoid absorption may be affected by a low intake of protein, fat, and dietary fiber.
\end{abstract}

Key Words green and yellow vegetables, dietary carotenoid intake, carotenoid determination

Many young unmarried subjects eat neither breakfast, nor any green or yellow vegetables, which take a lot of time to prepare. Green and yellow vegetables are rich in carotenoids, such as $\beta$-carotene, and vitamin C, minerals, and dietary fiber. Moreover, in Japanese, about $56 \%$ of the vitamin A in diet comes from green and yellow vegetables (1). Green and yellow vegetable intake is still lower than that recommended by the Japanese Ministry of Health, Labour and Welfare $(120 \mathrm{~g} / \mathrm{d}$, Health Japan 21). Therefore, we investigated the amounts and kinds of green and yellow vegetables consumed by young unmarried subjects.

One advantage of eating green and yellow vegetables is the intake of carotenoids. In recent years, carotenoids have attracted attention not only as a source of vitamin A, but also because of their reported contribution to antioxidation and inhibitory effects on cancer and various diseases (2-5). Therefore, it may be important to clarify the daily dietary carotenoid intake, and particularly, the differences in this intake among individual subjects. There are many reports (6-12) concerning carotenoid intake. However, the literature regarding the

E-mail: hosotani@center.wakayama-u.ac.jp intake in young unmarried subjects is scant. We performed a dietary survey during 3 consecutive days, and clarified the kinds and amounts of green and yellow vegetables frequently consumed. We selected the top 15 green and yellow vegetables in terms of intake, and determined the amounts of carotenoids ( $\beta$-carotene, $\alpha$ carotene, lycopene, $\beta$-cryptoxanthin and lutein+zeaxanthin) they contained. The carotenoid intake of each subject was calculated from the intake of the vegetables and the amounts of carotenoids.

Moreover, it has been reported that the absorption of carotenoids is affected by the amount of protein, fat, and dietary fiber (13-17) in a diet. It is suggested that the intake of protein, fat and dietary fiber differs among young subjects and may affect carotenoid absorption. We calculated the amounts of fat, protein, and dietary fiber taken in by individual subjects and investigated the relationship in terms of intake between carotenoid and protein, fat, and dietary fiber.

\section{METHODS}

1. Subjects and period of the survey. The subjects were 190 young unmarried workers (102 males and 88 females) and 129 students (57 males and 72 females) 
at a university in Wakayama Prefecture. They were aged $18-19 \mathrm{y}(17.2 \%), 20-24 \mathrm{y}$ (56.2\%), 25-29y $(18.6 \%), 30-34 \mathrm{y}(6.7 \%)$ and $35 \mathrm{y}-(1.3 \%)$. The survey was performed between early July and early August 1993.

2. Methods of survey. A questionnaire survey was performed. The questionnaire consisted of a survey of dietary habits, awareness of diet, and food intake. In the survey of food intake, the names of dishes and foods and their amounts (determined by weight) during 3 consecutive days, excluding Saturday and Sunday, were described in detail using an entry example as a reference. Attention was drawn to the following 3 points: 1 ) for foods that cannot be weighed, the standard weight should be described in detail according to the entry example. 2) All foods and beverages consumed during meals should be recorded, along with the time of consumption. 3) For foods eaten out, such as those from restaurants, takeout foods and foods eaten at cafeterias, dishes and contents should be remembered and described in as much detail as possible.

The questionnaire recovery rate was $61.5 \%$ for the students, $72.4 \%$ for the workers, and $67.9 \%$ for all subjects. In the food intake survey, the intake of nutrients was calculated from the food intake during $3 \mathrm{~d}$ in each subject using "Health Make Program ver. 4.0" (Health Make System Laboratory, use of the Standard Tables of Food Composition in Japan, Version 4).

3. Determination of amounts of carotenoids in green and yellow vegetables. Based on the food intake survey, the top 15 green and yellow vegetables in terms of intake were selected and purchased in a supermarket in Wakayama City. These 15 accounted for $98.6 \%$ of the intake of green and yellow vegetables in males and females. For the analysis of carotenoids in green and yellow vegetables, amounts of $\beta$-carotene, lutein + zeaxanthin, $\alpha$-carotene, lycopene, and $\beta$-cryptoxanthin in vegetables were analyzed using a modified Wills' method (18).

Five grams of sample was homogenized in $20 \mathrm{~mL}$ of acetone containing $0.05 \mathrm{~g}$ of pyrogallol and $0.25 \mathrm{~g}$ of magnesium carbonate. The acetone extraction was repeated four times. The combined acetone solution was transferred to a brown separating funnel. Seventy milliliters of diethyl ether (containing 0.025\% BHT) was added and mixed, and then $50 \mathrm{~mL}$ aliquots of $10 \%$ sodium chloride solution were added and mixed by shaking. The lower phase was drawn off and extracted three times with $70 \mathrm{~mL}$ aliquots of diethyl ether. The combined diethyl ether phases were evaporated at $35^{\circ} \mathrm{C}$ to near dryness. Sixty milliliters of diethyl ether was added, the residue was redissolved, and an equal volume of $20 \%$ potassium hydroxide in $\mathrm{MeOH}$ was added and saponified for $1 \mathrm{~h}$ at room temperature. Seventy milliliters of $10 \%$ sodium chloride solution was added and shaken in a brown separating funnel. The lower phase was drawn off and extracted three times with 60 $\mathrm{mL}$ aliquots of diethyl ether. The combined diethyl ether phases were washed with water until neutral, and were dehydrated with sodium sulfate anhydride, evaporated,

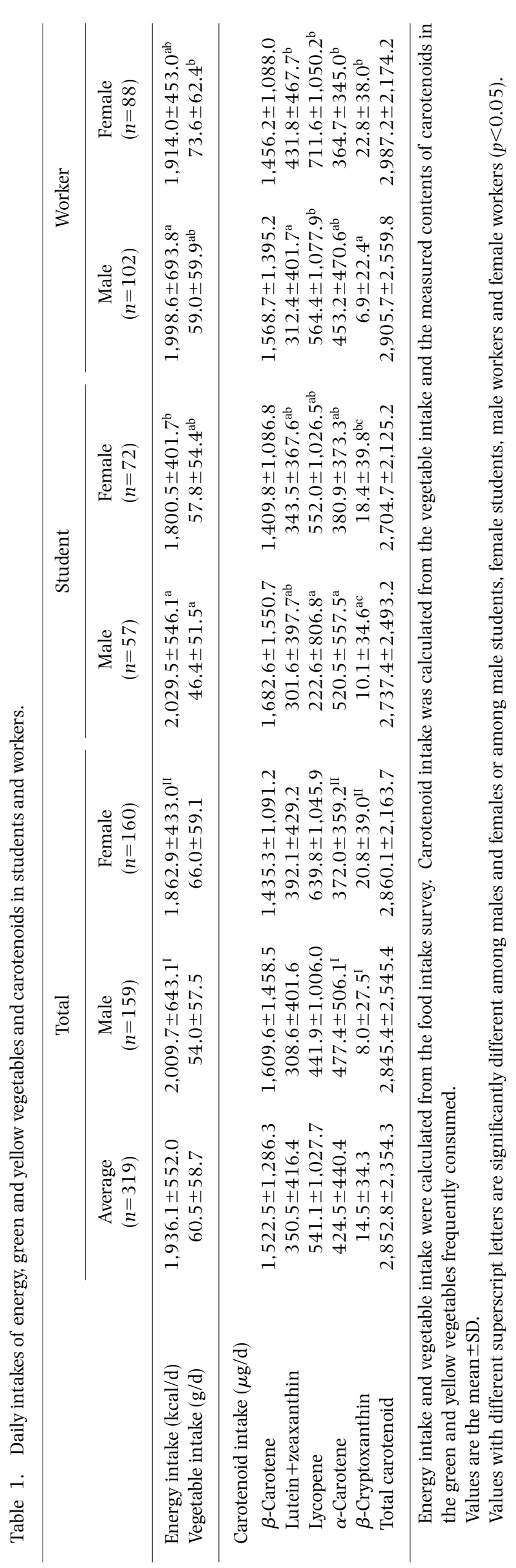


Table 2. Daily intakes and carotenoid contents of green and yellow vegetables.

\begin{tabular}{|c|c|c|c|c|c|c|c|}
\hline & \multicolumn{2}{|c|}{ Intake/d (g/d) } & \multirow{2}{*}{\multicolumn{2}{|c|}{ 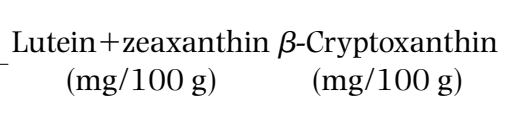 }} & \multirow{2}{*}{$\begin{array}{l}\text { Lycopene } \\
(\mathrm{mg} / 100 \mathrm{~g})\end{array}$} & \multirow{2}{*}{$\begin{array}{l}\alpha \text {-Carotene } \\
(\mathrm{mg} / 100 \mathrm{~g})\end{array}$} & \multirow{2}{*}{$\begin{array}{l}\beta \text {-Carotene } \\
(\mathrm{mg} / 100 \mathrm{~g})\end{array}$} \\
\hline & Male & Female & & & & & \\
\hline Tomato & 17.7 & 25.6 & $0.138 \pm 0.015$ & & $2.496 \pm 0.185$ & & $0.436 \pm 0.063$ \\
\hline Carrot & 15.6 & 12.0 & $0.260 \pm 0.051$ & & & $3.066 \pm 0.374$ & $8.006 \pm 1.216$ \\
\hline Pumpkin & 4.0 & 10.3 & $1.586 \pm 1.066$ & $0.202 \pm 0.011$ & & & $1.697 \pm 0.205$ \\
\hline Green sweet pepper & 4.7 & 3.9 & $0.368 \pm 0.138$ & & & & $0.289 \pm 0.041$ \\
\hline Ha-negi & 3.6 & 2.8 & $1.518 \pm 0.139$ & & & & $1.384 \pm 0.167$ \\
\hline Spinach & 4.0 & 2.4 & $2.075 \pm 0.580$ & & & & $2.945 \pm 0.543$ \\
\hline Pods (Sayaingen) & 1.2 & 2.3 & $0.331 \pm 0.060$ & & & & $0.329 \pm 0.049$ \\
\hline Broccoli & 0.3 & 1.7 & $0.306 \pm 0.078$ & & & & $0.309 \pm 0.045$ \\
\hline Komatsuna & 0.0 & 1.1 & $1.886 \pm 0.131$ & & & & $2.426 \pm 0.376$ \\
\hline Qing gin cai & 1.3 & 1.0 & $0.740 \pm 0.100$ & & & & $1.070 \pm 0.043$ \\
\hline Okra & 0.2 & 0.7 & $0.461 \pm 0.047$ & & & & $0.453 \pm 0.093$ \\
\hline Asparagus & 0.1 & 0.5 & $0.229 \pm 0.021$ & & & & $0.147 \pm 0.041$ \\
\hline Chinese chive & 0.6 & 0.3 & $1.339 \pm 1.058$ & & & & $2.469 \pm 0.290$ \\
\hline Immature pods (Sayaendo) & 0.2 & 0.3 & $0.277 \pm 0.017$ & & & & $0.413 \pm 0.077$ \\
\hline Sweet peppers & 0.3 & 0.3 & $0.365 \pm 0.034$ & & & & $0.333 \pm 0.042$ \\
\hline
\end{tabular}

Intake was calculated from the food intake survey. Carotenoid contents of green and yellow vegetable were determined by Wills' method.

and redissolved in $10 \mathrm{~mL}$ of $n$-hexane. The sample solution was used for high performance liquid chromatography (HPLC). For the analysis, HPLC was performed under the following conditions: column, Resolve C18 $5 \mu \mathrm{m}(150 \times 3.9 \mathrm{~mm}$ ID) (Waters, Milford, MA, USA); mobile phase, acetonitrile : dichloromethane : methanol : water : 1-octanol (100: $40: 10: 5: 0.15)$; column temperature, $30^{\circ} \mathrm{C}$; flow rate, $0.8 \mathrm{~mL} / \mathrm{min}$; and detection wavelength, $451 \mathrm{~nm}$.

4. Statistical analysis. Most values are shown as the mean \pm standard deviation. The mean value was compared between groups with a one-way analysis of variance, and differences were analyzed using Fisher's least significant difference method; $p<0.05$ was regarded as significant. Moreover, the mean value was compared between males and females using Student's $t$-test. The correlation between the intake of each nutrient and that of green and yellow vegetables was analyzed. Statistical processing was analyzed using "Excel Tokei" (Social Survey Research Information, Japan).

\section{RESULTS}

\section{Energy and green and yellow vegetable intake/d}

As shown in Table 1, the energy intake was significantly larger in males $(2,009.7 \pm 643.1 \mathrm{kcal} / \mathrm{d})$ than females $(1,862.9 \pm 433.0 \mathrm{kcal} / \mathrm{d})(p<0.05)$. The mean green and yellow vegetable intake/d in all subjects was $60.5 \pm 58.7 \mathrm{~g}$. The intake was greater in females $(66.0 \mathrm{~g} / \mathrm{d})$ than in males $(54.0 \mathrm{~g} / \mathrm{d})$, and the mean intake was greater in workers $(65.1 \mathrm{~g} / \mathrm{d})$ than in students $(52.5 \mathrm{~g} / \mathrm{d})$. Some $35.2 \%$ of males and $24.4 \%$ of females had very low intakes $(<25 \mathrm{~g} / \mathrm{d})$. That is to say, the intake of vegetables was greater in females but the intake of energy was greater in males.

As shown in Table 2, in males, intake/d/subject was highest for tomatoes, followed in order by carrots and green sweet peppers. In females, the intake was highest for tomatoes, followed by carrots and then pumpkins. The mean intake/d of tomatoes was $25.6 \mathrm{~g}$ in the females and $17.7 \mathrm{~g}$ in the males, while that of carrots was $12.0 \mathrm{~g}$ and $15.6 \mathrm{~g}$, respectively. The pumpkin intake in the females was $10.3 \mathrm{~g}$, which was about 2.6 times that in the males.

In males, intake/d/subject was highest for tomatoes, followed in order by carrots, green sweet peppers, pumpkin, spinach, ha-negi, qing gin cai, pods, Chinese chive, broccoli, sweet peppers, okra, immature pods, asparagus, and komatsuna.

2. Analysis of carotenoid levels in green and yellow vegetables and carotenoid intake/d

An analysis of carotenoid levels in the top 15 green and yellow vegetables in terms of intake was performed to calculate the carotenoid intake of each subject. Lutein+zeaxanthin and $\beta$-carotene were detected in each type of vegetable as shown in Table 2. In addition, lycopene was detected in tomatoes, $\alpha$-carotene in carrots, and $\beta$-cryptoxanthin in pumpkins. The lutein + zeaxanthin content was high in leafy vegetables.

Using these measurements and the intake of green and yellow vegetables, the amount of each carotenoid ingested was calculated (Table 1). In all subjects, total carotenoid intake/d was $2,852.8 \pm 2,354.3 \mu \mathrm{g}$, and the mean intake was $1,522.5 \pm 1,286.3 \mu \mathrm{g}$ for $\beta$-carotene, $350.5 \pm 416.4 \mu \mathrm{g}$ for lutein +zeaxanthin, $541.1 \pm 1,027.7$ $\mu \mathrm{g}$ for lycopene, $424.5 \pm 440.4 \mu \mathrm{g}$ for $\alpha$-carotene, and $14.5 \pm 34.3 \mu \mathrm{g}$ for $\beta$-cryptoxanthin. The intake of $\beta$ carotene and $\alpha$-carotene was higher in males than females. It is thought that the intake of carrots, which contain large amounts of $\beta$-carotene and $\alpha$-carotene, was greater in males than in females. On the other hand, the intake of lutein+zeaxanthin, lycopene, and $\beta$-cryptoxanthin was greater in females. In particular, 

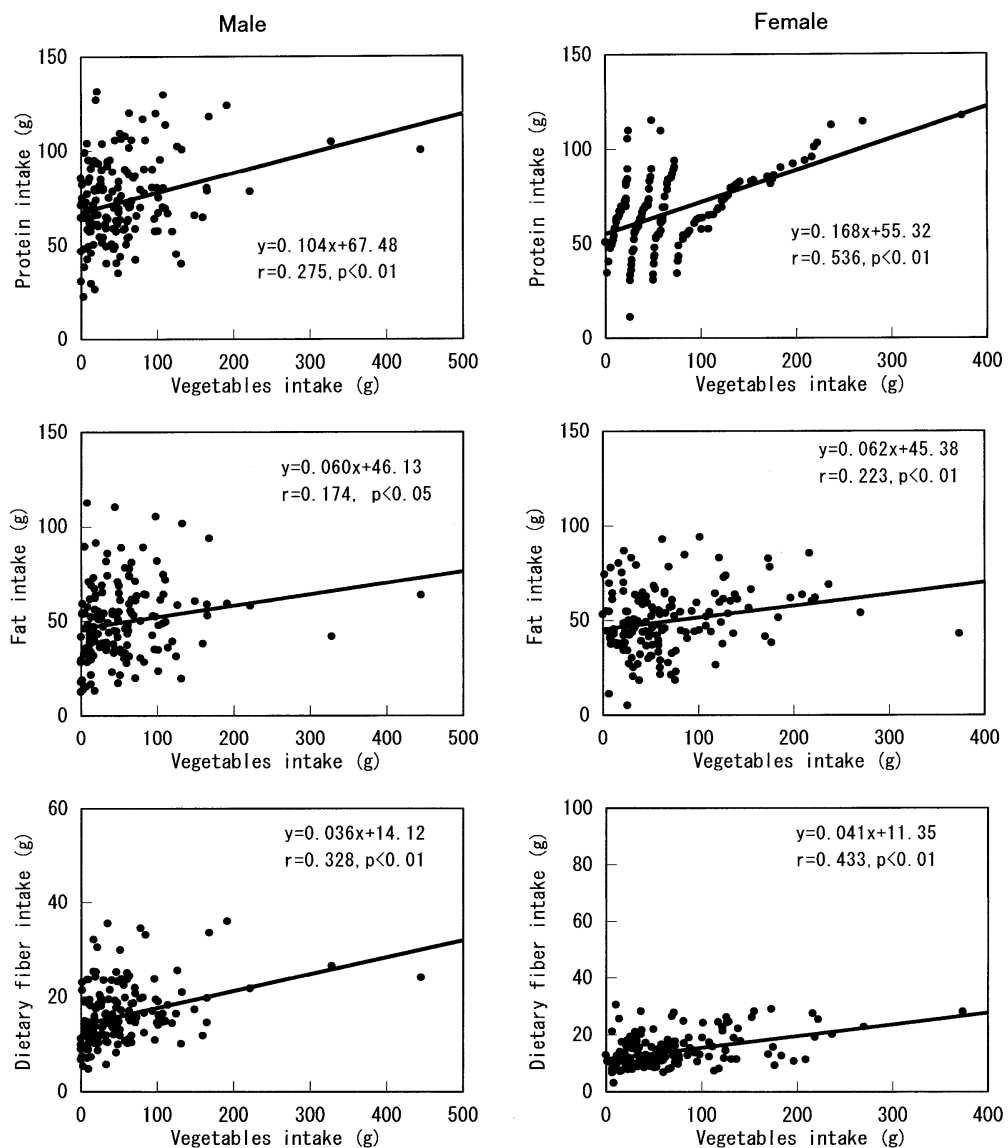

Fig. 1. Correlation between the green and yellow vegetable intake and protein intake, fat intake and dietary fiber intake. Green and yellow vegetables intake, protein intake, fat intake, dietary fiber intake are calculated from the food intake survey.

the intake of $\beta$-cryptoxanthin was significantly higher in females. Moreover, the intake of all carotenoids, lycopene, and lutein+zeaxanthin was greater in workers than in students. This may be because the intake of tomatoes was significantly higher in workers $(25.3 \mathrm{~g})$ than in students $(16.3 \mathrm{~g})$.

Though not shown in the figure, the distribution of total carotenoid intake/d was evaluated in males and females. Among males and females, the percentage of subjects with a total carotenoid intake of $<2,000 \mu \mathrm{g} / \mathrm{d}$ was $45.9 \%$ and $45.3 \%$, of $2,000-4,000 \mu \mathrm{g} / \mathrm{d}$ was $29.6 \%$ and $30.2 \%$, of $4,000-6,000 \mu \mathrm{g} / \mathrm{d}$ was $15.7 \%$ and $13.9 \%$, and of $\geq 6,000 \mu \mathrm{g} / \mathrm{d}$ was $8.8 \%$ and $10.6 \%$, respectively.

3. Relationship between intake of green and yellow vegetables and intake of protein, fat, and dietary fiber

Effects of protein, fat, and dietary fiber on the absorption of carotenoids have been reported and so correlations between the intake of green and yellow vegetables and that of protein, fat, and dietary fiber were calculated, as shown in Fig. 1.

The coefficient of the correlation with protein, was 0.275 in males $(p<0.01)$, and 0.536 in females $(p<0.01)$. The subjects with a high intake of green and yellow vegetables had a high intake of protein, but the subjects with a low intake of these vegetables had a low intake of protein; therefore a low intake of protein may affect carotenoid absorption.
The coefficient of the correlation between the intake of green and yellow vegetables and that of fat, was 0.174 in males $(p<0.05)$, and 0.223 in females $(p<0.01)$, lower than that between the vegetables and protein or dietary fiber. However, subjects with a fat intake of $<59 \mathrm{~g} / \mathrm{d}$ (fat allowance $\times 0.9$ ) composed $80.4 \%$ of the male group with a green and yellow vegetable intake of $<25 \mathrm{~g} / \mathrm{d}$, but $63.9 \%$ of that with a green and yellow vegetable intake of $\geq 75 \mathrm{~g} / \mathrm{d}$. Fat allowances were calculated according to Health Make Program ver. 4.0: Fat allowance $(\mathrm{g})=$ energy allowance $\times 0.23$ (fat energy ratio)/9. In the females, the subjects with a fat intake of $<46 \mathrm{~g} / \mathrm{d}$ (fat allowance $\times 0.9$ ) accounted for $51.3 \%$ of the group with a green and yellow vegetable intake of $<75 \mathrm{~g} / \mathrm{d}$, but $31.9 \%$ of the group with an intake of $\geq 75 \mathrm{~g} / \mathrm{d}$. Therefore, it was thought that the subjects with a high intake of green and yellow vegetables had a high intake of fat.

The coefficient of the correlation between the intake of green and yellow vegetables and that of dietary fiber was 0.328 in males $(p<0.01)$, and 0.433 in females $(p<0.01)$. Green and yellow vegetable are thought to contain much dietary fiber; therefore, the intake of dietary fiber correlated with the intake of these vegetables.

\section{DISCUSSION}

The intake of green and yellow vegetables was higher 
in the 2002 National Nutrition Survey $(88.5 \mathrm{~g} / \mathrm{d})(1)$ than in the 1993 survey $(81.69 \mathrm{~g} / \mathrm{d})(19)$. However, it was still lower than the recommended intake $(120 \mathrm{~g} / \mathrm{d}$, Health Japan 21), possibly due in part to a lack of understanding about the need for green and yellow vegetables in the young, including unmarried individuals. Kasamatsu (20) reported that the intake of these vegetables $(68.5 \mathrm{~g} / \mathrm{d})$ in Wakayama Prefecture, where the present study was conducted, was much lower than the national average $(81.69 \mathrm{~g} / \mathrm{d}, 1993)$. The National Nutritional Survey in 1993 (19) reported a mean green and yellow vegetable intake of $57.0 \mathrm{~g}$ in subjects aged $20-29 \mathrm{y}$ who live alone $(54.0 \mathrm{~g}$ in males and $60.9 \mathrm{~g}$ in females), which was similar to the mean value for all subjects in the current study. Among the unmarried subjects of this study, the intake was lower in males than females. Moreover, it was lower in students than workers. The percentage of subjects taking in $<57 \mathrm{~g} / \mathrm{d}$ (average) of green and yellow vegetables was $59.6 \%$, but the percentage of taking in $>120 \mathrm{~g} / \mathrm{d}$ (recommended intake) was $12.9 \%$. The difference in the intake of green and yellow vegetables among subjects was great.

Carotenoid levels in 15 kinds of green and yellow vegetable were determined in order to calculate the intake of carotenoids. The amount of lutein+zeaxanthin in spinach has been reported to be $4.40 \mathrm{mg}$ (21) or $9.89 \mathrm{mg} / 100 \mathrm{~g}(22)$ and that in broccoli, 0.80-2.44 mg (22-24), much higher than the values in this study. The $\beta$-carotene content of carrots has been reported to be $4.65-9.02 \mathrm{mg}$ (22) or $7.60 \mathrm{mg} / 100 \mathrm{~g}$ (25), while that of spinach has been reported to be $3.30 \mathrm{mg}(21)$ and $4.31 \mathrm{mg} / 100 \mathrm{~g} \mathrm{(25),} \mathrm{similar} \mathrm{to} \mathrm{the} \mathrm{values} \mathrm{obtained}$ here. However the amount of $\beta$-carotene in broccoli has been reported to be $0.78 \mathrm{mg} / 100 \mathrm{~g} \mathrm{(23)}$ and that in asparagus, $0.49 \mathrm{mg} / 100 \mathrm{~g} \mathrm{(23),} \mathrm{higher} \mathrm{than} \mathrm{the} \mathrm{values}$ in this study. On the other hand, the $\alpha$-carotene content of carrots has been reported to be $0.53 \mathrm{mg}(21)$, 3.06$4.89 \mathrm{mg}$ (22), or $3.79 \mathrm{mg} / 100 \mathrm{~g} \mathrm{(25)}$ and the lycopene content of tomatoes has been reported to be $3.10 \mathrm{mg} /$ $100 \mathrm{~g}(25)$, which were also close to the values in the present study. The variation may be explained by difference in the analytical methods used, the conditions and periods of cultivation, the length of storage, and the varieties in different countries and regions.

In this study, the intake was $2,852.8 \mu \mathrm{g} / \mathrm{d}$ for carotenoids overall, $1,522.5 \mu \mathrm{g} / \mathrm{d}$ for $\beta$-carotene, $350.5 \mu \mathrm{g} /$ $\mathrm{d}$ for lutein+zeaxanthin, $541.1 \mu \mathrm{g} / \mathrm{d}$ for lycopene, $424.5 \mu \mathrm{g} / \mathrm{d}$ for $\alpha$-carotene, and $14.5 \mu \mathrm{g} / \mathrm{d}$ for $\beta$-cryptoxanthin. It has been reported that in various foreign countries, the intake of carotenoids was 1,120-6,382 $\mu \mathrm{g} / \mathrm{d}$ for $\beta$-carotene, 500-6,025 $\mu \mathrm{g} / \mathrm{d}$ for lutein+zeaxanthin, 1,310-10,844 $\mu \mathrm{g} / \mathrm{d}$ for lycopene, 527-1,174 $\mu \mathrm{g} / \mathrm{d}$ for $\alpha$-carotene, and $25-247 \mu \mathrm{g} / \mathrm{d}$ for $\beta$-cryptoxanthin (subjects aged 24-79 y) (6-9). Further, the following values were reported in Japan: 1,889-2,762 $\mu \mathrm{g} / \mathrm{d}$ for $\beta$-carotene, and a mean intake of $181-306 \mu \mathrm{g}$ for $\alpha$-carotene and 1,731-3,326 $\mu \mathrm{g}$ for lycopene (subjects aged 40-69 y) (10-12). The intake of $\alpha$-carotene and $\beta$-carotene in this study was similar to the mean from a previous study in Japan, but the lutein+zeaxanthin, lycopene, and $\beta$-cryptoxanthin intakes were lower than those reported previously. The amount of lycopene from processed tomato-based foods (ketchup and tomato juice) was added to the intake in this study. However, the levels of lycopene, lutein+zeaxanthin, and $\beta$-cryptoxanthin ingested were low. It is thought that less tomato, pumpkin, and spinach were consumed by the subjects in this study than in the previous study in Japan. However, there were few subjects with a high carotenoid intake in this study. The percentage of subjects with a total carotenoid intake of $\geq 6,000 \mu \mathrm{g} / \mathrm{d}$ was just $9.7 \%$. It was clarified that the difference in carotenoid intake among the subjects was large.

The interaction between the consumption of green and yellow vegetables and the intake of fat, protein, or dietary fiber was analyzed in order to investigate the effect of the latter on the absorption of carotenoids. Figure 1 showed that subjects with a high intake of green and yellow vegetables have a high intake of protein and fat, and that subjects with a low intake of green and yellow vegetables have a low intake of protein and fat. It is reported that the amount of carotenoid absorbed was increased by adding fat (6-200 g) to basic meals (containing $60-137 \mathrm{~g} / \mathrm{d}$ of fat) $(13,14)$. These studies were based on one test meal. Therefore, it is suggested that the absorption of carotenoids was influenced by the consecutive intake of fat and protein in the present study. There are reports that dietary fiber does $(16,17)$ and does not (15) affect the absorption of carotenoids. In the current study, the intake of dietary fiber was significantly greater in the group with a high intake of green and yellow vegetables (Fig. 1). The amount of carotenoid absorbed may be influenced by the intake of dietary fiber.

This study has several limitations. First, the intake of $\beta$-cryptoxanthin may have been seriously underestimated, because the major source of $\beta$-cryptoxanthin is citrus fruits. The carotenoids from fruit were not included in this study. Second, since the survey was only carried out in summer, the vegetables consumed were seasonal.

From the results of our analysis, the subjects who ate few green and yellow vegetables had small intakes of fat, protein, and dietary fiber. In contrast, those who ate many green and yellow vegetables had large intakes of fat, protein, and dietary fiber. Moreover, because the individual variation in the amounts of green and yellow vegetables consumed was extensive, the variation in carotenoid intake from these vegetables was great. It is important that the effect of fat, protein, and dietary fiber on the absorption and metabolism of carotenoids be investigated, and that the influence of large or small amounts of these carotenoids on the health of subjects be clarified.

\section{REFERENCES}

1) Ministry of Health and Welfare. 2004. Kokumin Eiyou no Genjou (Results of National Nutrition Survey, 2002). Daiichi Shuppan Publishers, Tokyo (in Japanese). 
2) Mozaffarieh M, Sacu S, Wedrich A. 2003. The role of the carotenoids, lutein and zeaxanthin, in protecting against age-related macular degeneration: a review based on controversial evidence. Nutr J 2: 20.

3) Yuan JM, Stram DO, Arakawa K, Lee HP, Yu MC. 2003. Dietary cryptoxanthin and reduced risk of lung cancer: the Singapore Chinese Health Study. Cancer Epidemiol Biomarkers Prev 12: 890-898.

4) Michaud DS, Feskanich D, Rimm EB, Colditz GA, Speizer FE, Willett WC, Giovannucci E. 2000. Intake of specific carotenoids and risk of lung cancer in 2 prospective US cohorts. Am J Clin Nutr 72: 990-997.

5) Osganian SK, Stampfer MJ, Rimm E, Spiegelman D, Manson J, Willet WC. 2003. Dietary carotenoids and risk of coronary artery disease in women. Am J Clin Nutr 77: 1390-1399.

6) Chopra M, O'Neill ME, Keogh N, Wortley G, Southon S, Thurnham DI. 2000. Influence of increased fruit and vegetable intake on plasma and lipoprotein carotenoids and LDL oxidation in smokers and nonsmokers. Clin Chem 46: 1818-1829.

7) Slattery ML, Benson J, Curtin K, Ma KN, Schaeffer D, Potter JD. 2000. Carotenoids and colon cancer. Am J Clin Nutr 71: 575-582.

8) Curran-Celentano J, Hammond BR Jr, Ciulla TA, Cooper DA, Pratt LM, Danis RB. 2001. Relation between dietary intake, serum concentrations, and retinal concentrations of lutein and zeaxanthin in adults in a Midwest population. Am J Clin Nutr 74: 796-802.

9) Mannisto S, Smith-Warner SA, Spiegelman D, Albanes D, Anderson K, van den Brandt PA, Cerhan JR, Colditz G, Feskanich D, Freudenheim JL, Giovannucci E, Goldbohm RA, Graham S, Miller AB, Rohan TE, Virtamo J, Willett WC, Hunter DJ. 2004. Dietary carotenoids and risk of lung cancer in a pooled analysis of seven cohort studies. Cancer Epidemiol Biomarkers Prev 13: 40-48.

10) Sasaki S, Ushio F, Amano K, Morihara M, Todoriki O, Uehara Y, Toyooka E. 2000. Serum biomarker-based validation of a self-administered diet history questionnaire for Japanese subjects. J Nutr Sci Vitaminol 46: 285-296.

11) Kim MK, Sasazuki S, Sasaki S, Okubo S, Hayashi M, Tsugane S. 2003. Effect of five-year supplementation of vitamin $\mathrm{C}$ on serum vitamin $\mathrm{C}$ concentration and consumption of vegetables and fruits in middle-aged Japanese: a randomized controlled trial. J Am Coll Nutr 22: 208-216.

12) Imaeda $N$, Tokudome $Y$, Ikeda M, Kitagawa I, Fujiwara N, Tokudome S. 1999. Foods contributing to absolute intake and variance in intake of selected vitamins, minerals and dietary fiber in middle-aged Japanese. J Nutr Sci Vitaminol 45: 519-532.

13) Prince MR, Frisoli JK. 1993. $\beta$-Carotene accumulation in serum and skin. Am J Clin Nutr 57: 175-181.

14) Brown MJ, Ferruzzi MG, Nguyen ML, Cooper DA, Eldridge AL, Schwartz SJ, White WS. 2004. Carotenoid bioavailability is higher from salads ingested with full-fat than with fat-reduced salad dressings as measured with electrochemical detection. Am J Clin Nutr 80: 396-403.

15) Rock CL, Swendseid ME. 1992. Plasma beta-carotene response in humans after meals supplemented with dietary pectin. Am J Clin Nutr 55: 96-99.

16) Castenmiller JJ, West CE, Linssen JP, van het Hof KH, Voragen AG. 1999. The food matrix of spinach is a limiting factor in determining the bioavailability of betacarotene and to a lesser extent of lutein in humans. $J$ Nutr 129: 349-355.

17) Riedl J, Linseisen J, Hoffmann J, Wolfram G. 1999. Some dietary fibers reduce the absorption of carotenoids in women. J Nutr 129: 2170-2176.

18) Wills RB, Hazli Nurdin H, Wootton M. 1988. Separation of carotenes and xanthophylls in fruit and vegetables by HPLC. J Micronutr Anal 4: 87-98.

19) Ministry of Health and Welfare. 1995. Kokumin Eiyou no Genjou (Results of National Nutrition Survey, 1993). Daiichi Shuppan Publishers, Tokyo (in Japanese).

20) Kasamatsu T. 2000. Regional differences and changes in the five-year period of nutritional status based on the prefectural nutrition survey. Jpn J Nutr 58: 169-176.

21) Heinonen MP, Ollilainen V, Linkola EK, Varo PT, Koivistoinen PE. 1989. Carotenoids in Finnish foods: vegetables, fruits, and berries. J Agric Food Chem 37: 655-659.

22) Muller H. 1997. Determination of carotenoid content in selected vegetables and fruit by HPLC and photodiode array detection. Z Lebensm Unters Forsch A 204: 88-94.

23) Holden JM, Eldrige AL, Beecher GR, Buzzard IM, Bhagwat S, Davis CS, Douglass LW, Gebhardt S, Haytwitz D, Schakel S. 1999. Carotenoids content of U.S. food: an update of the database. J Food Compos Anal 12: 169196.

24) Hart DJ, Schott KJ. 1995. Development and evaluation of an HPLC method for the analysis of carotenoids in foods, and the measurement of the carotenoids content of vegetables and fruits commonly consumed in the UK. Food Chem 54: 101-111.

25) Hirota S, Kon M. 1993. Carotenoids in vegetables and fruits. Jpn J Nutr 51: 293-316. 